\title{
Disaster Recovery and Reconstruction Following the 2011 Great East Japan Earthquake and Tsunami: A Business Process Management Perspective
}

\author{
Natt Leelawat $^{1} \cdot$ Anawat Suppasri $^{2} \cdot$ Fumihiko Imamura $^{2}$
}

Published online: 24 September 2015

(c) The Author(s) 2015. This article is published with open access at Springerlink.com

\begin{abstract}
The Tohoku Regional Bureau (TRB) of the Ministry of Land, Infrastructure, Transport and Tourism (MLIT) performed various actions in response to the 2011 Great East Japan Earthquake and Tsunami. The total disaster recovery and reconstruction period is expected to last for 10 years, of which the first five years are regarded as the concentrated reconstruction period. As of 2013, a majority of the mega projects that involved restoration actions have been completed, which indicates a more effective rate of completion compared with the MLIT projects performed in normal non-disaster situations. This short article explains the management process of the recovery and reconstruction utilized by the TRB - an interorganizational process-from a business process management (BPM) perspective and creates a simple organization construction diagram of the entire process. The study focused on the transactions and actor roles to identify their strengths. The findings indicate the utilization of different operational procedures in some parts of the process, the importance of liaison role, as well as some obstacles. The lessons learned from this analysis can assist managers and researchers in designing and managing restoration processes for future disasters.
\end{abstract}

Natt Leelawat

leelawat.n.aa@m.titech.ac.jp

1 Department of Industrial Engineering and Management, Graduate School of Decision Science and Technology, Tokyo Institute of Technology, Tokyo 152-8552, Japan

2 International Research Institute of Disaster Science, Tohoku University, Sendai, Miyagi 980-0845, Japan
Keywords Business process management - Disaster reconstruction · Disaster recovery $\cdot 2011$ Great East Japan Earthquake and Tsunami

\section{Introduction}

The 2011 Great East Japan Earthquake and Tsunami was one of the largest disasters in recorded history. The east coast of Japan experienced damage and the destruction of more than 400,000 buildings (NPA 2011). Twenty highway routes, 171 national road sections, and 536 local road sections were closed, and several bridges were damaged (IDI 2011). Twenty-two railways, including the Tohoku Shinkansen, remained inoperative for one month after the earthquake (TRB 2013). Sendai Airport suffered a collapsed roof in its terminal. This disaster presented many challenges to the Government of Japan, especially the Ministry of Land, Infrastructure, Transport and Tourism (MLIT), which is responsible for the main transportation systems and infrastructure. This article focuses on the recovery and reconstruction of the infrastructure and transportation systems.

Japan's recovery and reconstruction plans consist of national, prefectural, municipal, and residential level plans (IRP et al. 2013). The affected municipalities proposed their plans; applied for a special zone or reconstruction grant within the prefecture, which was coordinated with the regional office of each ministry; and proposed the plan at the national level (to the Reconstruction Agency). The municipalities were then able to formulate a plan; arrange, coordinate, and supervise the budget; implement the plan; and distribute the budget to the relevant ministries (IRP et al. 2013). 
Table 1 Disaster recovery and reconstruction policy and planning stages in Japan

\begin{tabular}{ll}
\hline Stage & Description \\
\hline I (0 to 4 months) & 1.1 The disaster headquarters are established \\
& 1.2 Basic guidelines and an act are issued (within 4 months) \\
& 1.3 The first supplementary budget is passed (within 1.5 months) \\
& 2.1 Provisional reconstruction headquarters is established \\
II (4 to 11 months) & 2.2 Basic recovery plans are prepared by prefectures and municipalities \\
& 2.3 Two additional supplementary budgets are adopted \\
& 3.1 A reconstruction agency and special zone for reconstruction are designated \\
III (11 months to 10 years) & 3.2 The fourth supplementary budget is passed \\
& 3.3 Disaster recovery and reconstruction is implemented via flexible grants and policies
\end{tabular}

Source IRP et al. (2013)

The total recovery and reconstruction period was expected to take 10 years and require JPY 23 trillion (USD 290 billion) funding (IRP et al. 2013). Marjanovic and Hallikainen (2013) analyzed related studies in the context of business process management (BPM) and disaster recovery and discovered new challenges and opportunities to apply BPM research to disaster recovery. This article analyzes the disaster recovery and reconstruction process from the BPM perspective.

This empirical study aimed for providing insights into the characteristics of recovery and reconstruction and gaining an understanding of research areas across BPM and disaster management. The findings are discussed while considering the characteristics of recovery plans, as described by Mileti (1999).

\section{Research Design}

Following several previous disaster-related studies, Design and Engineering Methodology for Organizations (DEMO) (Dietz 2006) was selected. This study is the first to apply DEMO while considering recovery and reconstruction in the disaster phase.

Data collection and interviews with TRB officers were performed from May to June 2013 in Sendai, Japan. Faceto-face, semistructured interviews were performed in June 2013 with the Director of the Disaster Prevention Division and the Planning Subdivision Chief of the Disaster Prevention Division, the Planning Department of the Tohoku Regional Bureau (TRB)/MLIT. This division has a principle role in the recovery and reconstruction process. The interviews focused on the overall plans, operations, and activities related to recovery and reconstruction following the 2011 Great East Japan Earthquake and Tsunami, and facilitated an open discussion to assess the details of each activity.
The data analysis was conducted based on the PerformaInforma-Forma Analysis (Dietz 2006) to obtain the ontology of the overall process. The results of the transaction type were identified. Subsequently, the executor roles, the initiator roles, and all links between them were specified for each transaction type. The outcome is an organization construction diagram (OCD).

\section{Analysis of the Disaster Recovery and Reconstruction Process}

Japan's national-level disaster recovery and reconstruction policy and planning procedures consist of three stages (Table 1). In addition to the establishment of organizations, laws, and guidelines, the recovery and reconstruction process primarily involves a special zone for the reconstruction-designated supplementary budget and flexible grants and policies (stage III).

The Seven Principles for the Reconstruction Framework were issued by the advisory panel consisting of respected intellectuals, academics, religious figures, and elected officers (IRP et al. 2013). In June 2011, based on the final report from the Reconstruction Design Council in Response to the Great East Japan Earthquake, the government issued the Basic Guidelines and Basic Act on Reconstruction (GOJ 2011; Reconstruction Agency 2011; IRP et al. 2013).

Recovery and reconstruction has been promoted by various public agencies and has been administered by the MLIT (2012). These processes are applicable to many projects, such as the employment of various measures for coasts (the Sendai Airport and wastewater treatment plants), rivers (restoration of levee sections and measures against liquefaction), sewage (plant treatment and coordination of plant reconstruction with municipalities), roads (restoration of expressways and state roads and the 
reconstruction of $224 \mathrm{~km}$ roads), railways (restoration of the Sanriku Railway and the JR Sen-Seki Line), airports (quake-resistant design projects), and seaports (restoration of port facilities), and act as measures against sediment disasters in risk areas (MLIT 2012). The MLIT also assisted with other projects, such as the promotion of town reconstructions (MLIT 2012).

The MLIT promoted a steady recovery and reconstruction process that should be carefully planned and implemented because they will represent the recovery and reconstruction model for future disasters. "Steady" indicates slowly but surely. Miyagi Prefecture included a detailed protection plan for a 100-year tsunami (IRP et al. 2013).

The OCD developed in this study is shown in Fig. 1. The elementary actor roles include a recovery manager (A1), a situation checker (A3), a recovery executor (A4), a reconstruction manager (A5), and a surveyor (A6), whereas the composite actor roles include a decision maker (CA2), a budget provider (CA7), a consultant (CA8), a construction business (CA9), and a reconstruction executor (CA10). The recovery and reconstruction process begins from the recovery management transaction (T1) executed by the recovery manager (A1). A1 can access the disaster data (AT1), which are the damage and loss records reported by each public agency. The results of this transaction prompt the decision maker (CA2) to consider the need for recovery or reconstruction. In the case of recovery, A1 requests the situation checker (A3) to assess the condition of a real location. Then, A3 requests the recovery executor (A4) to recover (T4) the specific area. Once T4 is completed, T3 is also completed. In the case of reconstruction, A1 requests that the reconstruction manager (A5) complete the reconstruction project (T5). Because the reconstruction case is more extensive than the recovery case, other transactions are included in the root transaction T5. First, A5 requests that the surveyor (A6) survey the conditions of the assigned location. Next, A5 requests four composite (external) actor roles to execute four transactions: a budget provider (CA7) to provide the budget (T7) for the

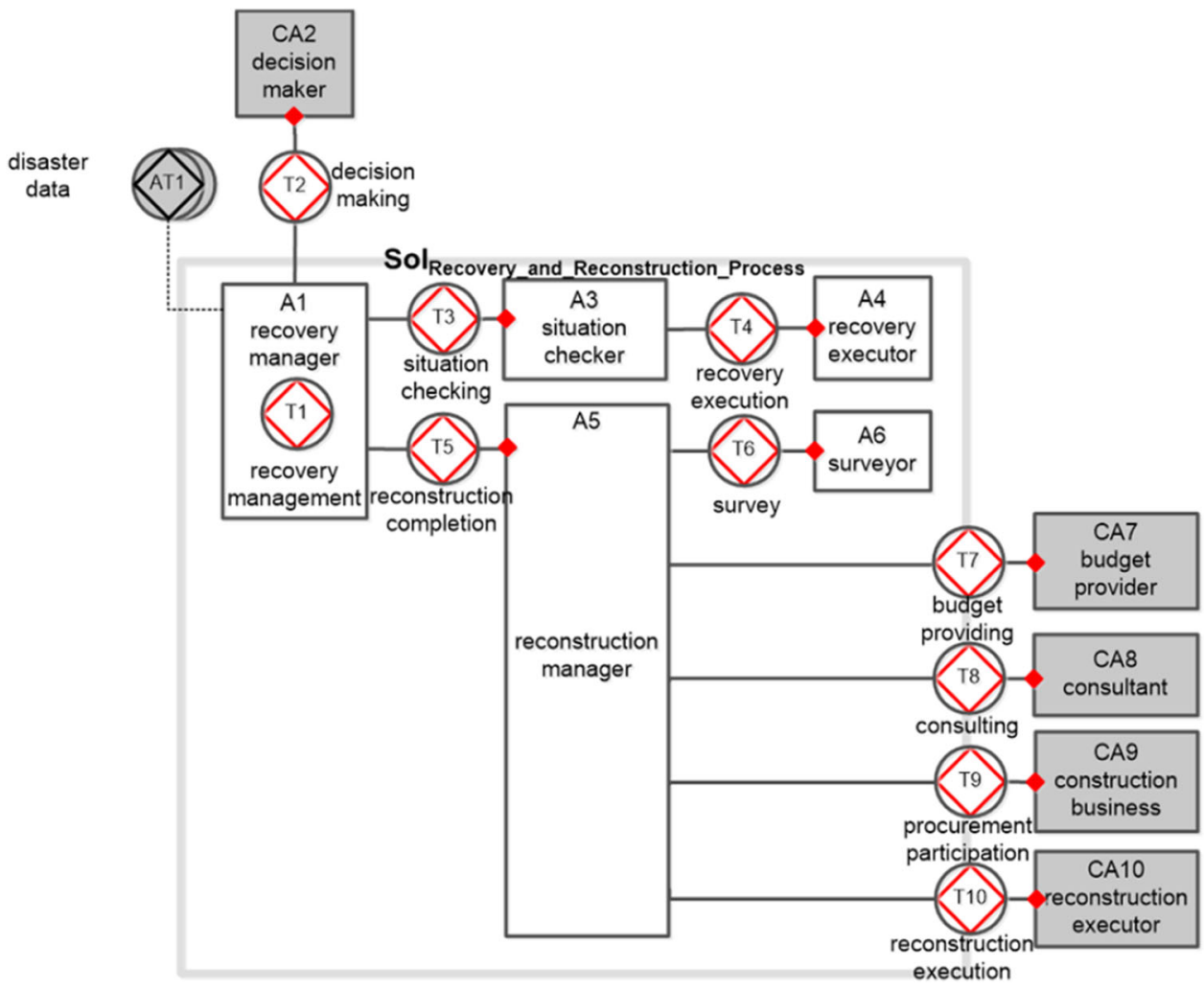

Fig. 1 Organization construction diagram (OCD) of the disaster recovery and reconstruction process. Note OCD's notation (Perinforma 2012, p. 50): (1) elementary actor role $\mathrm{A}_{i}$ : an operating unit of an organization; (2) composite (external) actor role $\mathrm{CA}_{k}$ : environmental actor role; (3) initial link (solid line): connection between the actor role who is the initiator and the transaction type; (4) executor link (solid line with diamond): connection between the actor role who is the executor and the transaction type; (5) transaction type $\mathrm{T}_{j}$ : the "container for all coordination facts that are created in all transactions of this transaction type, up to the current time ... in the state interpretation, transaction symbols are called transaction banks"; (6) scope of interest $\mathrm{SoI}_{k}$ : the boundary used to separate the composition and the environment; (7) aggregate transaction type $\mathrm{AT}_{i}$ : collection of "one of more transaction types"; and (8) information link (dot line): the "access right of an actor role to the content of the connected transaction bank" 
reconstruction project, a consultant (CA8) for project consultations (T8), a construction business (CA9) to participate in procurement (T9), and a reconstruction executor (CA10) to reconstruct the assigned project (T10).

Areas that experienced minor damage were recovered via the urgent removal of debris, whereas others required additional effort for reconstruction. Based on the interviews, the scope of interest (SoI $\mathrm{I}_{\text {Recovery_and_Reconstruction_Process }}$ ) containing T3 and T4 cannot be fixed because each area utilizes different operational procedures. In certain areas, both of these techniques were implemented by public agencies of the MLIT. Simultaneously, several areas hired local construction businesses, which are considered to be actor roles from other agencies that only participated in the recovery execution or both the situation assessment and the recovery execution (that is, only $\mathrm{T} 1$ was solely executed by government agencies). Thus, the SoI $I_{\text {Recovery_and_Reconstruction_Process }}$ is dependent on the disaster area conditions. From the perspective of process management, this SoI differs from the SoI of typical business processes because the recovery and reconstruction process entails large-scale efforts that encompass a variety of conditions.

Recovery and reconstruction projects have been ongoing since 2011. As of 2013, a majority of the plans had been completed. Based on the interviewees' opinions, these processes are being performed nearly three-times faster than for typical reconstruction projects.

Several problems have been encountered in the recovery and reconstruction projects, such as the "lack of technical experts and technicians"; "shortages in materials, including liquid concrete and etc."; and "difficulties in acquiring bidders for projects and obtaining land" (MLIT 2013, p. 107). Moreover, a lack of prior agreement regarding intercity recovery and reconstruction collaboration was noted. The projects can continue because all actor roles operate under the same chain of command (GOJ and MLIT) and are governed by the guidelines and laws (Basic Guidelines for Reconstruction in Response to the Great East Japan Earthquake and the Basic Act on Reconstruction in Response to the Great East Japan Earthquake) that were established to place the municipalities and residents at the center of the recovery and reconstruction process and to increase coordination among many organizations (IRP et al. 2013).

Another vital role of the MLIT is the Liaison Council for Smooth Execution of Recovery and Reconstruction Projects (MLIT 2012). The liaisons have been established to help each organization communicate, update, share, and gather information and progress because these organizations are very busy conducting their duties. As a result, each actor role can understand the progress and status of other actor roles. Consistent with Marjanovic and Hallikainen (2013), this vital role has enhanced the efficiency of the total collaboration by enabling a mutual understanding of the recovery and reconstruction process.

\section{Discussion and Conclusions}

The disaster recovery goal "is for survivors to regain stability in their lives, livelihoods, and housing" (Maly and Shiozaki 2012, p. 56), whereas the goal of reconstruction is to "build a safe city," "pursue an ideal city," and "[recover] the functions of a disaster-stricken area and [restore] normal lives to disaster victims" (Murosaki 2007, p. 330). By applying BPM, the OCD explains the entire recovery and reconstruction process for the abstract levels. Several insights were obtained from this diagram. We determined the components that should be considered in a plan; thus, the lessons learned should be applied to future planning. Based on the lessons learned from this case, the following discussion explains and enriches these findings via Mileti's (1999) identified characteristics of successful local disaster recovery and reconstruction plans.

Community Involvement: Several transactions (for example, T3, T4, and T6) require the involvement of the community to facilitate an understanding of the context of the area and necessary information. As suggested by Mileti (1999), stakeholders should collaborate with policy makers to reduce conflicts in the plan development stage. We must "realize the importance of preserving original human relationships in local communities and transforming those community ties into the energy needed for reconstruction efforts" (Murosaki 2007, p. 333).

Information: Numerous cross-boundary transactions (for example, T7 and T8) and more efficient information sharing can provide greater efficiency. As Marjanovic and Hallikainen (2013, p. 35) noted, one of the challenges of the recovery process is the "sharing of process-related knowledge across diverse contexts, organizational boundaries and professional boundaries." The role of the liaison is very important when assisting several organizations/areas, especially if intercity plan is not prior established. It is also consistent with the lessons learned from previous earthquakes: a common reconstruction vision must be shared (Murosaki 2007).

Organization: The government and other organizations serve the same roles in actual implementation, which requires a distinct definition of the authority and responsibility of these actor roles to maintain the quality and efficiency of related transactions. For example, Sasaki (2013) suggested hiring fixed-term personnel to prevent a lack of expert human resources. Therefore, a clear definition of the scope of the required work is necessary to enable the hiring of fixed-term employees. 
Procedures: The implementation of the OCD differs for different areas. Because this case study is a scenario- or situation-based process versus a routine process, the efficiency of the recovery and reconstruction process is dependent on how we can successfully match the roles in the OCD with existing actors and local resources.

Damage Evaluation: There are two steps for damage evaluation (T3 and T6). Information is collected to determine whether recovery or reconstruction should be performed and to rapidly assess the recovery objectives.

Finances: A realistic implementation of $\mathrm{T} 7$ is significantly more complex than shown in the OCD. In practice, additional steps or procedures must be performed for the affected municipalities to obtain reconstruction grants or special zone authorization at the prefectural and national levels. Thus, more efficient knowledge and information sharing is required among the affected municipalities and the various budget providers. Several financial problems were discovered. For example, the financial measures were not always geared toward local needs in the Iwate Prefecture. A solution to this problem that relies on greater information sharing is to "secure and enhance financial resources grounded in high-quality support from the government" (Sasaki 2013).

This short article discusses the application of BPM to a case study of the 2011 Great East Japan Earthquake and Tsunami recovery and reconstruction, identifying issues and explaining the characteristics identified by previous studies. This study can also help planners and policy makers understand the responsibility, authority, and competencies that support the preparation of a disaster management plan. As reported by IRP et al. (2013, p. 4), "Japan acted rapidly to establish a reconstruction planning framework based on mutual trust, respect, and collaboration among stakeholders." This recovery and reconstruction process can be considered as a model for future natural disasters.

Despite the involvement of many organizations, we decided to conduct interviews with a single principle managerial organization. Future studies should consider conducting interviews with other related organizations to identify additional perspectives. Quantitative studies should be conducted to evaluate the performance and practical conditions of this case and to investigate sustainable recovery and reconstruction projects.

Acknowledgments The authors would like to acknowledge the Ministry of Education, Culture, Sports, Science and Technology, the Academy for Co-creative Education of Environment and Energy Science (ACEEES) of Tokyo Institute of Technology, and the International Research Institute of Disaster Science (IRIDeS) of Tohoku University for this research opportunity, as well as the Director of Disaster Prevention Division, the Chief of Planning Subdivision, Disaster Prevention Division, and the First Chief of Policy Division from the Tohoku Regional Bureau of the MLIT for their collaboration. The authors would also like to acknowledge Prof. Junichi Iijima and Iijima Laboratory (Tokyo Tech); and the editor and all four anonymous reviewers for their useful comments and suggestions.

Open Access This article is distributed under the terms of the Creative Commons Attribution 4.0 International License (http://creative commons.org/licenses/by/4.0/), which permits unrestricted use, distribution, and reproduction in any medium, provided you give appropriate credit to the original author(s) and the source, provide a link to the Creative Commons license, and indicate if changes were made.

\section{References}

Dietz, J.L.G. 2006. Enterprise ontology-Theory and methodology. Berling: Springer.

GOJ (Government of Japan). 2011. Basic act on reconstruction in response to the Great East Japan Earthquake. Tokyo: GOJ.

IDI (Infrastructure Development Institute-Japan). 2011. The restorations from the Great East Japan Earthquake and Tsunami. IDI Quarterly 56: 1-12.

IRP (International Recovery Platform), T. Tanaka, Y. Shiozaki, A. Hokugo, and S. Bettencourt. 2013. Reconstruction policy and planning. Washington, DC: World Bank.

Maly, E., and Y. Shiozaki. 2012. Towards a policy that supports people-centered housing recovery-Learning from housing reconstruction after the Hanshin-Awaji Earthquake in Kobe, Japan. International Journal of Disaster Risk Science 3(1): 56-65.

Marjanovic, O., and P. Hallikainen. 2013. Disaster recovery-New challenges and opportunities for business process management research and practice. Pacific Asia Journal of the Assocication for Information Systems 5(1): 23-44.

Mileti, D.S. 1999. Disaster by design: A reassessment of natural hazards in the United States. Washington, DC: Joseph Henry Press.

MLIT (Ministry of Land, Infrastructure, Transport and Tourism). 2012. White paper on land, infrastructure, transport and tourism in Japan, 2011. Tokyo: MLIT.

MLIT (Ministry of Land, Infrastructure, Transport and Tourism). 2013. White paper on land, infrastructure, transport and tourism in Japan, 2012. Tokyo: MLIT.

Murosaki, Y. 2007. Lessons on reconstruction strategies from the Great Hanshin-Awaji Earthquake. Journal of Disaster Research 2(5): 330-334.

NPA (National Police Agency). 2011. Damage condition of the 2011 earthquake off the Pacific coast of Tohoku. http://www.npa.go. jp/archive/keibi/biki/higaijokyo.pdf. Accessed 26 Jul 2013 (in Japanese).

Perinforma, A.P.C. 2012. The essence of organisation. South Holland: Sapio Enterprise Engineering.

Reconstruction Agency. 2011. Basic guidelines for reconstruction in response to the Great East Japan Earthquake. Tokyo: Reconstruction Agency.

Sasaki, K. 2013. Three years into reconstruction. Current status and prospects. Tokyo: Institute for International Studies and Training. http://www.iist.or.jp/en-m/2013/0220-0894/. Accessed 2 Apr 2014.

TRB (Tohoku Regional Bureau), Ministry of Land, Infrastructure, Transport and Tourism (MLIT). 2013. Response of Tohoku Regional Bureau, MLIT, to the Great East Japan Earthquake. Miyagi: TRB. 